\title{
Physical Aspects of Viral Membrane Fusion
}

\author{
Laura Wessels and Keith Weninger* \\ Department of Physics, North Carolina State University, Raleigh \\ E-mail: Irwessel@ncsu.edu, keith weninger@ncsu.edu
}

Received March 12, 2009; Revised May 30, 2009; Accepted June 12, 2009; Published August 11, 2009

Enveloped viruses commonly employ membrane fusion during cell penetration in order to deliver their genetic material across the cell boundary. Large conformational changes in the proteins embedded in the viral membrane play a fundamental role in the membrane fusion process. Despite the tremendously wide variety of viruses that contain membranes, it appears that they all contain membrane fusion protein machinery with a remarkably conserved mechanism of action. Much of our current biochemical understanding of viral membrane fusion has been derived from high-resolution structural studies and solution-based in vitro assays in which viruses fuse with liposomes or cells. Recently, single-particle experiments have been used to provide measurements of details not available in the bulk assays. Here we focus our discussion on the key dynamical aspects of fusion protein structure, along with some of the experimental and computational techniques presently being used to investigate viral-mediated membrane fusion.

KEYWORDS: viral membrane fusion; class I, II, and III fusion proteins; hemagluttin (HA); E1; gp64

\section{INTRODUCTION}

Membrane fusion is a vital phenomenon that allows eukaryotic cells to transfer materials among their membrane-encased compartments. Biological membranes do not spontaneously fuse under normal physiological conditions, so proteins are critical to mediate biological instances of membrane fusion. Eukaryotic cells have a highly conserved system of proteins known as SNAREs (soluble Nethylmaleimide-sensitive factor [NSF] attachment protein [SNAP] receptors) that control intracellular membrane fusion[1]. Fertilization, fusion of mitochondria, and cell-cell fusion processes during development each use distinct proteins for membrane fusion[2,3,4]. One of the most easily studied biological systems involving membrane fusion is infection of a cell by an enveloped virus[5,6,7]. Enveloped viruses commonly release their genomes into a cell by fusing with the plasma membrane or by fusing from within an endosome following endocytosis.

All instances of protein-mediated membrane fusion require surmounting significant kinetic and energetic barriers, and membrane fusion proteins allow these barriers to be overcome. The prefusion states of membrane fusion proteins are metastably positioned away from the global free-energy minimum. These proteins mediate fusion by a process involving large conformational changes to lower energy states[7,8,9,10]. 
The transition from the metastable state to the lower energy state for viral fusion proteins is triggered when a virus encounters a specific cue from a targeted cell. Enveloped viruses that are endocytosed by cells use the endosomal acidification to trigger the conformational changes that lead to membrane fusion. Other viruses are triggered to fuse with the plasma membrane of cells by other signals, e.g., coreceptor binding. In either case, the membrane remodeling mechanisms used by all viral fusion proteins to mediate fusion appear universal. First, the proteins change into a more extended conformation that allows the exposure of a hydrophobic fusion peptide that is initially buried within the untriggered protein. This extended conformation allows the fusion peptide to insert and bury itself into an opposing membrane. Viral membrane fusion proteins are anchored in the virus membrane by transmembrane domains. Thus, this extended, fusion-activated state, with the fusion peptide in the target membrane, cross-links the two membranes that are destined to fuse. The fusion protein then folds back on itself into a hairpin configuration, bringing the two apposing membranes into near contact. A series of intermediate states is thought to form at this point, involving various lipidic structures, including a hemifusion stalk, a single bilayer diaphragm, and a fusion pore. The free energy of these intermediate structures depends on their geometry, the properties of the lipids in the membranes, the interactions of the lipids with the transmembrane domain, and the fusion peptide of the proteins, and may be affected by cooperativity between multiple fusion proteins[11,12,13]. The opening of a fusion pore allows the viral capsid access to the interior of the cell where it can potentially initiate infection. X-ray crystallography, electron microscopy, biochemical assays, genetic studies, computational/theoretical modeling, and fluorescence microscopy have all contributed to this general picture of the molecular events during viral membrane fusion.

\section{FUSION PROTEIN STRUCTURE}

Viral membrane fusion proteins share some common features. All are integral membrane proteins with transmembrane domains that anchor them in the viral envelope. Viral fusion proteins often include domains inside the virus particle that are adjacent to the transmembrane domain. These internal domains are typically important for virus particle assembly, but appear to play no significant role in membrane fusion. The larger, external domains of the viral fusion proteins naturally separate into three classes based on common structural paradigms, leading to their classifications as class I, class II, or class III (described below and see Table 1). Regardless of the class, a common feature of the external domains is the presence of a short sequence of hydrophobic amino acids. This region is critical for membrane fusion activity and is called the fusion peptide.

TABLE 1

Properties of Class I, II, and III Fusion Proteins

\begin{tabular}{|c|c|c|c|}
\hline & Class I & Class II & Class III \\
\hline $\begin{array}{l}\text { Secondary structure of } \\
\text { fusion proteins[12] }\end{array}$ & Mainly $\alpha$-helical & $\begin{array}{l}\text { Mainly composed } \\
\text { of } \beta \text {-sheets }\end{array}$ & Mixed secondary structure \\
\hline $\begin{array}{l}\text { Location of fusion } \\
\text { peptide[13] }\end{array}$ & $\begin{array}{l}\text { Usually located } \\
\text { near N-terminus }\end{array}$ & Located internally & Located internally \\
\hline Postfusion structure[13] & Trimer of hairpins & Trimer of hairpins & Trimer of hairpins \\
\hline
\end{tabular}




\section{Class I Fusion Proteins}

The class I proteins are characterized by a central, triple-stranded, coiled-coil region, with outer carboxyl (C-) terminal antiparallel layers that are either mostly helical or adopt extended conformations, forming a trimer of helical hairpins. High-resolution crystallographic studies of the class I fusion glycoproteins from influenza HA[14], retroviruses (gp41 from human immunodeficiency virus [HIV][15], gp-41 from simian immunodeficiency virus [SIV][16], and gp21 from human T-lymphotropic virus[17]), and gp2 from Ebola virus[18] have all revealed similar structures[7,13]. Class I proteins commonly exist on virus particles as trimeric spikes that extend away from the particle membrane. The transmembrane anchor, the amino acid glycine-rich fusion peptide (varies from 10-30 amphiphilic amino acids), and the external folded domains all contribute to membrane fusion in the class I family.

Influenza HA is a prototype for the class I fusion proteins and is responsible for much of our present knowledge of viral membrane fusion. HA has been well characterized thanks to X-ray crystallography of three separate conformations relevant to the fusion process, which have guided many modeling efforts of membrane fusion[14]. Inspired by this detailed structural knowledge of HA, a de novo designed, coiledcoil system was recently created that has low-pH enhanced membrane fusion activity[19].

Influenza particles, like all type I fusion protein-containing viruses, are pleomorphic with most particles being spherical or oval, and having length scales of 100-200 nm. On average, influenza particles contain around $375 \mathrm{HA}$ spikes that extend approximately $12 \mathrm{~nm}$ out from the viral membrane surface[20]. The single chain precursor, HA0, cleaves into HA1 and HA2 on activation[14]. HA1 and HA2 compose the metastable neutral $\mathrm{pH}$ conformation of HA found on mature virus, i.e., the prefusion conformation. Terminal sialic acids of glycoproteins and glycolipids (i.e., gangliosides) are the cellular receptors for influenza. The hydrogen bonds and van der Waals contacts between sialic acid and the carbohydrate side chains of HA1 bind influenza to the cell at neutral $\mathrm{pH}[21,22,23]$. These receptor-bound particles are endocytosed. Acidic conditions are encountered along the endosomal transport pathway, at which point membrane fusion is triggered between the influenza particle and the endosome[24].

Several crystal structures of HA under different conditions, along with biochemical studies, have guided formulation of a model of the structural dynamics that lead to membrane fusion. A loop-to-helix transition in HA2 is thought to project the fusion peptide $100 \AA$ towards the endosomal membrane where it anchors irreversibly, thus creating a metastable, extended conformation in which both membranes are cross-linked by HA. Next, HA2 performs a reverse turn and jackknifes back, relocating the C-terminus by 100 Á towards the target membrane, thus bending the molecule in half like a hairpin (Fig. 1)[25]. The Cterminal, $\alpha$-helical coil interacts in an antiparallel fashion with the $\mathrm{N}$-terminal coil. In this way, the three HA proteins comprising a surface spike assemble into a "trimer of hairpins", where the transmembrane domain and fusion-peptide segments of each protein are together at the same end of the molecule. With the $\mathrm{N}$ - and C-terminus now adjacent to each other, membrane fusion can occur. This fusion-pH conformation is the lowest free-energy state characterized for HA2[26].

As of yet there is no consensus on what conformations and entry angles of HA are necessary to destabilize the lipid membranes sufficiently to activate fusion. Some studies suggest that only one HA trimer is necessary for binding and fusion, but other studies suggest that a complex of three or six trimers is required[27,28,29]. Also, the number and form of intermediate structures is still under debate[14].

Although all class I fusion proteins are thought to follow the general sequence of conformational changes seen in HA, not all of them use endocytosis to enter the cell or are triggered by exposure to acidic conditions. HIV, avian sarcoma/leukosis virus (ASLV), Sendai virus, and murine leukemia virus (MLV) all fuse directly to the plasma membrane at neutral $\mathrm{pH}[30,31]$. Fusion of HIV-1 is triggered by the interaction of the virus fusion proteins with a receptor and a coreceptor[32]. HIV-1 glycoprotein 120 (gp120) binds to the cell receptor CD4, usually found on helper T cells. Gp120 is loosely bound to gp41, which is embedded within the viral membrane[33]. A C-terminal antiparallel $\beta$-sheet forms the base of a trimeric protein spike. When HIV-1 binds to a cell, the interaction of gp120 with CD4 triggers a transition in gp120, allowing gp120 to interact with the secondary cell-surface receptors CXCR4 or CCR5[34,35]. Fusion between the viral membrane and the cellular membrane proceeds following an additional conformational change in gp41 


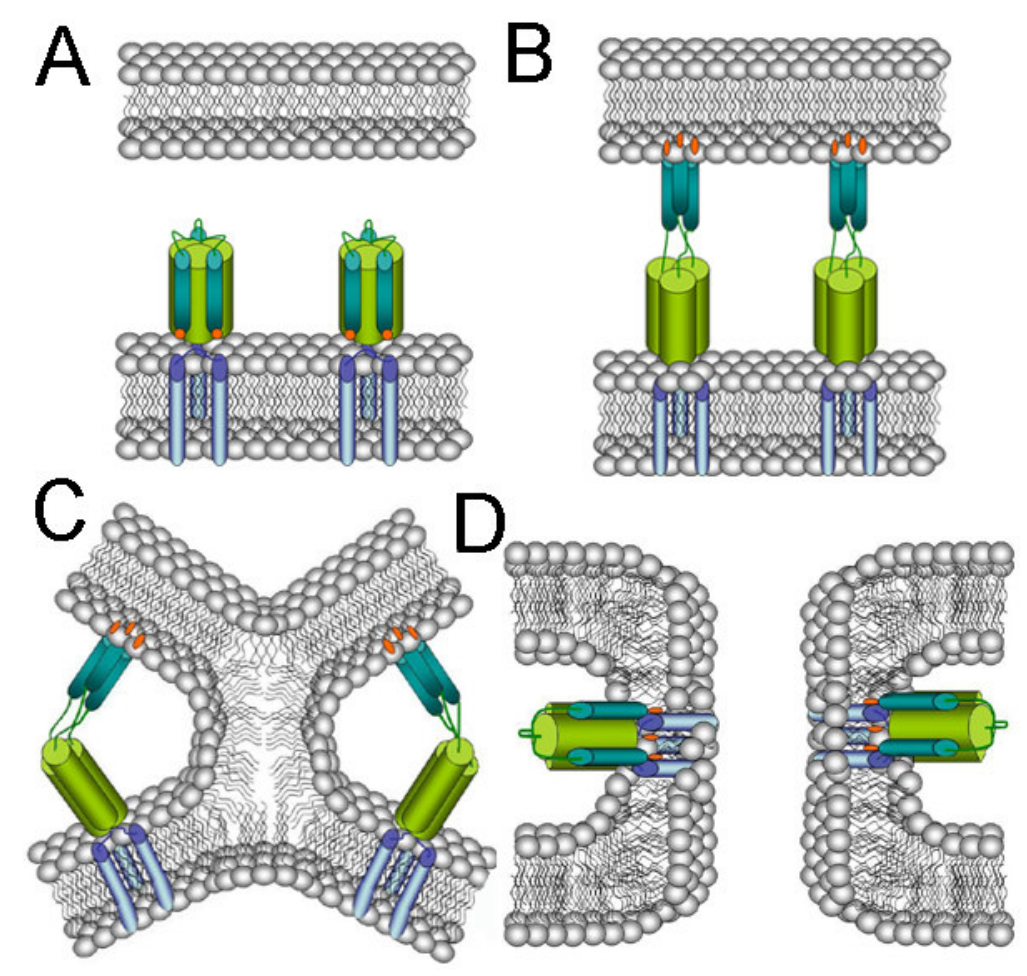

FIGURE 1. Conformational changes in influenza HA protein related to membrane fusion. (A) The trimeric membrane fusion protein spike assembly of influenza virus is anchored into the viral membrane in a preactivated state. Shown schematically, the transmembrane domain is dark blue, the $\mathrm{N}$-terminal fusion peptide is orange, the green cylinders depict $\alpha$-helical structures. On acidification, a hypothesized "extended intermediate" conformation is generated in which the hydrophobic fusion peptide is extended towards the targeted membrane. (B) After anchoring into the endosome's membrane, to cross-link the two membranes, the fusion protein folds back into a hairpin, positioning the transmembrane domain and fusion peptide in close proximity. (C) This hairpin forces the two membranes close together and is essential for the process, leading to full merging of the bilayers. (D) A fusion pore forms when the $\mathrm{C}$ - and $\mathrm{N}$-terminus are relocated adjacent to each other in the same membrane[62].

that results from the secondary receptor interactions[36]. Gp41 at low surface concentrations promotes fusion, whereas it leads to rupture at high surface concentrations[33]. Similar to HA, conformational changes in gp41 expose an N-terminal fusion peptide, which will insert into the cell membrane. The ability of short peptides (C34 and T-20, or enfuvirtide) to bind and stabilize an elongated form of gp41, inhibiting overall fusion, is the strongest evidence for the existence of an extended intermediate conformation for all fusion proteins on the pathway to membrane fusion[32,37,38,39,40,41,42]. Despite HIV's standing as the prototype for viruses that fuse at the plasma membrane, very recent experiments have challenged this view[43]. These recent studies found substantial evidence that membrane fusion within an endocytotic pathway is the dominant cell entry mechanism leading to productive infection for HIV.

\section{Class II Fusion Proteins}

Class II proteins are found in alphaviruses (E1 from Semliki Forest virus [SFV][44] and Sindbis virus [SIN][45]) and flaviviruses (E1 from hepatitis C virus [HCV][46,47,48]; E from tick-borne encephalitis [TBE][49], dengue fever[50], and West Nile virus[51]). Class II proteins are expressed as a single 
polypeptide precursor that is cleaved prior to the virus' release from the infected cell and long before entering the endocytotic pathway. The cleavage of p62 yields E1 and E2 in alphaviruses, and the cleavage of prM yields $\mathrm{E}$ and $\mathrm{M}$ in flaviviruses. $\mathrm{HCV}$ envelope proteins are not matured by a cellular endoprotease cleavage[46]. The E and E1 glycoproteins fold into three domains primarily composed of $\beta$-sheets[52].

Alphaviruses enter the cell via endocytosis[53], as shown by their ability to fuse with liposomes at low $\mathrm{pH}$ [54], although some evidence suggests alternate entry pathways[55,56]. SIN particles have 240 copies of E1, capsid, and E2. E1 and E2 form heterodimers with mostly $\beta$-barrel structures that are linked together to form an icosahedral structure ( $\mathrm{T}=4$ quasisymmetry) with an external diameter of $70 \mathrm{~nm}$. The icosahedral symmetry of class II proteins containing viruses is a key distinction from the class I protein containing viruses, but is similar to many nonenveloped viruses that do not contain membrane fusion proteins. Remarkably, recent structural investigations have suggested that despite the dramatically different initial conformations, the mechanisms of mediating membrane fusion appear nearly identical for class I and class II proteins[6,7,13,26,45,57]. Functional studies support this conclusion of similar fusion mechanisms for class I and II proteins[58,59].

E1 is responsible for cell fusion, and E2 is involved in receptor binding and cell entry. E1's fusion peptide lies near the dimerization domain, having many contacts with E2. Fusion requires the dissociation of the tightly packed E1-E2 heterodimers, exposure of the fusion peptide, and the formation of E1 homotrimers. On exposure to low pH, E1-E2 heterodimers rotate, moving the bulky E2 molecules out of the center of the prefusion assembly and allowing E1 homotrimeric spikes to form. These E1 spikes extend away from the virus surface. Because the E1 fusion protein is a major assembly element of the icosahedral prefusion lattice, these movements result in a major rearrangement of the viral surface.

The fusion peptide is located at the tip of the extended E1 spike, allowing it to embed in a targeted membrane. In the final postfusion state, the E1 molecule is bent at the central "hinge" domain, which is nearly centered between the fusion peptide and the C-terminal membrane anchor. This final conformation suggests that dynamic bending at the hinge allows E1 to transition from an extended conformation, crosslinking two membranes to a jackknifed conformation, bringing the viral membrane and the snared target membrane close together[26,44,50,52,57,59,60,61,62], similar to the dynamic motions in influenza HA and HIV gp41. Cryoelectron microscopy revealed that the E1 transmembrane domain becomes bent and does not completely traverse the membrane in the final postfusion state, suggesting a role for transmembrane domain-induced stress in the bilayers during fusion[57].

\section{Class III Fusion Proteins}

Class III proteins combine structural elements from both class I and class II fusion proteins. The fusion domain in class III proteins contains two fusion loops at the tip of an elongated $\beta$-sheet similar to the class II proteins. However, the postfusion state is similar to the $\alpha$-helical, hairpin-like trimeric core seen in class I proteins[13,63]. Baculovirus gp64[64], vesicular stomatitis virus (VSV) G[65], and herpes simplex virus type 1 (HSV-1) gB[66] proteins are suggested to be class III proteins.

For most fusion proteins, a single trimer refolding releases more free energy than is required to overcome the barrier to fusion. Rhabdoviruses are unusual in that the energy available from refolding one trimer is insufficient to catalyze fusion[63,67]. Therefore, for this virus family, multiple fusion trimers are required to associate before fusion can occur[68].

\section{Similarities to SNARE Proteins}

Intriguingly, some of the same structural features seen in the viral fusion proteins are also present in the eukaryotic cellular fusion proteins, the SNAREs[1]. SNARE proteins are present in all eukaryotic cells on multiple compartments and mediate fusion between cellular transport vesicles, e.g., synaptic vesicles and the cell membrane[69]. SNAREs are membrane proteins anchored to membranes by either single-pass 
transmembrane domains or palmitolyation. The heteromeric complex formed from SNARE proteins (the SNARE complex) is composed of two transmembrane-containing SNAREs that bind to each other along with additional SNARE proteins and additional factors (e.g., Sec9, Munc18, complexin, etc.). Formation of this complex brings two apposing membranes together in a manner very similar to viral membrane fusion proteins[70,71,72,73]. On complex assembly, the transmembrane domains of SNAREs in each membrane cross-link the membranes and positions them at the same end of a coiled coil of helicies[74], similar to the final configuration of viral fusion proteins with the transmembrane domain and fusion peptides closely positioned in the jackknifed, folded-back conformation. When complementary sets of SNAREs are anchored in opposed membranes, complex assembly provides the energy necessary to connect these membranes and overcome the repulsive forces that would otherwise prevent fusion[75]. The precise mechanisms connecting SNARE protein folding and protein-lipid interactions to membrane fusion continue to be open questions. Nevertheless, the similarities in structures between SNARE complexes and viral fusion proteins when cross-linking membranes destined to fuse suggest that the mechanism of achieving membrane fusion is common.

\section{THE ROLE OF LIPIDS IN MEMBRANE FUSION}

Membrane fusion proteins ensure close apposition of the membranes during fusion phenomena; yet, simply forcing membranes into close proximity is not sufficient to yield membrane fusion. Protein-free bilayers will not spontaneously fuse with each other even when separated by only $2-3 \mathrm{~nm}[8,76]$, which demonstrates the crucial role of interactions between fusion proteins and lipids for fusion. The presence of certain lipid species and lipid derivatives within the bilayers can also strongly promote or inhibit fusion, likely by modulating the spontaneous curvature of bilayers[31,77,78,79]. Lipid composition may also be critical for recruitment of other proteins to the plasma membrane, organization of membrane domains for fusion, and regulation of fusion protein complexes[78].

Cellular plasma membranes contain many different classes of lipids with different molecular shapes and charge distributions, including phosphatidylcholine (PC), phosphatidylserine (PS), phosphatidylinositol (PI), phosphatidylethanolamine (PE), cholesterol $(\mathrm{CH})$, and sphingomyelin (SM). $\mathrm{CH}$ and sphingolipids form lipid raft domains within the lipid bilayer[80,81]. These lipid raft domains are involved in the entry, assembly, and budding of viral structural proteins for some enveloped viruses. Lipid raft domains influence cell entry for influenza, Ebola, Marburg, Epstein-Barr, and HSV-1[21,35]. HA binds to sialic acid moieties present on glycolipids that are often clustered in rafts within the cell membrane. Interactions between the transmembrane domain and lipids cause HA to concentrate in lipid rafts[35]. Flavivirus fusion is enhanced by $\mathrm{CH}$; however, $\mathrm{CH}$ is not absolutely required for fusion[26]. SFV and SIN require the sterol 3 $\beta$-hydroxyl group in $\mathrm{CH}$ for cell binding and entry; however, they do not require lipid rafts for fusion[31,79]. E1's binding and acid-dependent conformational changes are both inhibited by a lack of $\mathrm{CH}$ in the target membrane[58,82,83].

In vitro experiments using carefully designed blends of specific lipids can arrest fusion at a specific stage or inhibit fusion altogether, providing critical insights into the fusion process[84,85]. Inverted coneshaped lipids, such as PS or lysophosphatidylcholine (lysoPC), promote positive spontaneous curvature in the bilayer. These lipids inhibit fusion when present in the outer monolayers of membranes, but promote fusion between these same membranes' inner monolayers by enhancing formation of a fusion pore. Conversely, lipids that promote negative spontaneous curvature in the bilayer, such as PE, enhance fusion between outer monolayers, but arrest fusion between inner monolayers, leading to a hemifusion structure that resembles a stalk[8,86,87].

This stalk structure has been observed in a static configuration between bilayers composed of diphytanoylphosphatidylcholine (DPhPC) $[88,89]$. For that observation, the bilayers were first brought into contact by dehydration. Further reduction of the intervening water resulted in formation of stalks at the interbilayer contact points. In viral membrane fusion experiments where tracers have been placed both in the membrane as well as within the aqueous compartment of the target structure, it has been shown that 
outer lipid monolayer leaflets exchange molecules before aqueous compartments merge (Fig. 2), which suggests that the stalk forms before the fusion pore opens[27,54,89,90,91,92]. No consensus on a model of the organization of a fusion protein-containing lipid hemifusion stalk has been reached.

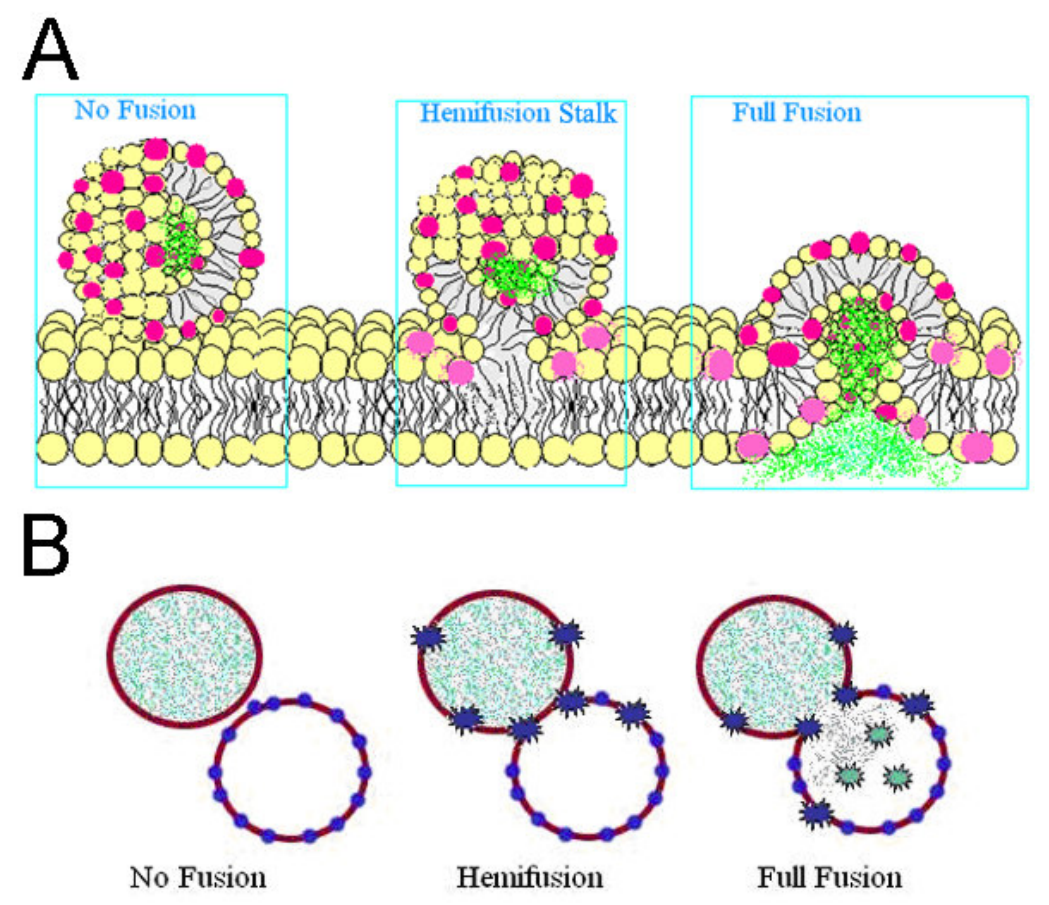

FIGURE 2. Fluorescent lipid-like dyes incorporated into a virus membrane can report on lipid mixing occurring during hemifusion, but detection of content mixing is required to confirm pore formation and full fusion. (A) Fusion of a vesicle with membrane and content dye to an unlabeled planar bilayer. (B) Fusion of a membrane-labeled vesicle to a content-labeled vesicle.

The free energy of the stalk structure is dependent on its geometry and the properties of the lipid monolayer[ $[88,89]$. The bending of bilayers away from their preferred spontaneous curvatures is resisted by the required changes in both the packing density of the lipid head groups on the surface and the lipid acyl chains within the hydrophobic core of the bilayer (see Fig. 1C)[77]. Prior to forming a fusion pore in a stalk, the inner monolayers may pucker inward and touch, a state called transmembrane contact (TMC). The TMC may then expand radially outward forming a hemifusion diaphragm (HD) (Fig. 3)[76]. Another possibility is that partial insertion of the fusion loops and fusion peptides into the outer leaflet of the target membrane deform the bilayers. This partial insertion could displace the lipid head groups on the outer leaflet, resulting in a difference in area between the inner and outer leaflet, thus causing the bilayer to curve into a nipple-like cap. For influenza, the formation of a cap on the HA2 helical bundle would make pore formation irreversible[7,87,93].

Tension or compression in the bilayers can be exasperated or relieved by osmotic gradients. A compressive (negative) osmotic gradient will press lipid material from the inner or outer leaflet towards the void, promoting pore formation. A swelling (positive) gradient has the opposite effect, pressing lipid material from the void toward the outer leaflet, inhibiting pore formation. Lipids with natural tendencies toward membrane curvature, either positive or negative, also influence the energy balance in these intermediate structures. Some conditions in a hemifused stalk can generate an unstable, flickering fusion pore that will either open fully, allowing for the exchange of material between aqueous compartments, or collapse[76,94]. It is not absolutely necessary for proteins to participate in hemifusion stalks or fusion 


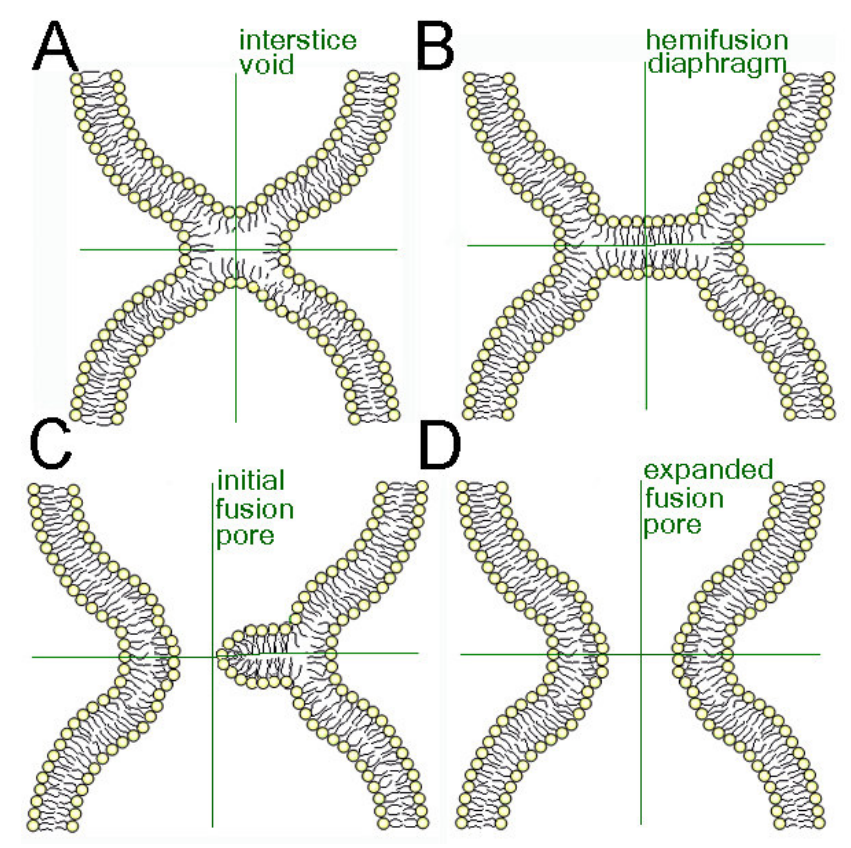

FIGURE 3. Hemifusion diaphragm (HD) in membrane fusion. (A) Voids in the junction of fusing membranes create steep energy barriers. (B) Membrane tilt and formation of HD lower the energy barrier. (C) Formation of a fusion pore begins when the HD's radius expands beyond the membrane's thickness generating a rupture near the HD's rim. This fusion pore may flicker in and out of existence before becoming stable. (D) As the HD continues to expand, the pore becomes large enough for the RNA/DNA to pass through it[11,76].

pores, as evidenced by the fact that pores are seen in protein-free liposome systems where poly(ethylene glycol) and dehydration were used to fuse the vesicles without a hemifusion intermediate[95].

A direct role for the transmembrane domain in the mechanism of membrane fusion has been revealed by experiments using engineered HA in which the transmembrane domain has been replaced by a glycosylphosphatidylinositol (gpi) lipid anchor. In these experiments without the transmembrane domain, membrane fusion is arrested at the hemifusion state with no fusion pore forming even after very long times. Whether the transmembrane domain serves to couple forces created by protein folding into the bilayer, disrupts the lipid packing, or contributes structurally to the transmembrane pore remains a point of debate[96,97,98,99].

The actions of the fusion peptide on the lipid bilayers are as important to the overall membrane fusion process as the role of the lipids and the lipid-transmembrane domain interactions. Mutations in the short fusion peptide have a very large effect on the efficiency of fusion[100,101,102,103,104]. A mechanistic understanding of how fusion peptides promote fusion is incomplete despite a number of theories about modes of action including curvature induction, membrane rupture promotion, or direct force transduction[105].

Cooperative interactions of the membrane-contacting domains of the fusion proteins may also be fundamental to membrane fusion. Baculovirus gp64 requires associations between viral proteins for membrane fusion. For other fusion proteins, cooperativity is likely, although not energetically, necessary. The possibility of protein interactions led to speculation that a ring-like complex of glycoproteins around the hemifusion stalk might restrict lipid flow between the bilayers. If proteins form a loosely packed ring around the TMC, then lipids will be able to mix within the stalk, allowing for lipid mixing without content mixing (Fig. 4). If proteins are packed tightly in a ring around the TMC, then lipid flow will be restricted between outer leaflets and content mixing may precede lipid mixing[9,67]. Protein cooperativity 

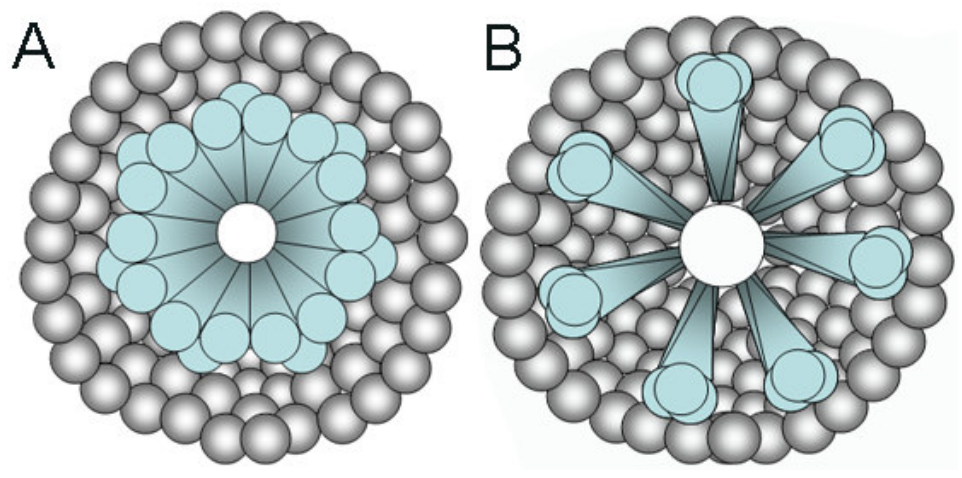

FIGURE 4. Top view of two models of details of the fusion pore in a lipid bilayer. Proteins are the light blue and lipids are the gray circles. (A) Lipids are prevented from mixing between the two membranes by a tight collar assembled from several fusion proteins. (B) The assembly of transmembrane domains of multiple fusion proteins at the fusion pore is loose enough to allow lipids to diffuse between the two membranes[28].

has also been suggested for other membrane fusion protein phenomena, including SNARE-mediated fusion[106]. In the SNARE system, the energy required for hemifusion between outer leaflets was experimentally determined to be $1.4 \mathrm{~kJ} / \mathrm{mol}$. The same SNARE experiment determined that pore formation between inner leaflets required $5.5 \mathrm{~kJ} / \mathrm{mol}[70]$. Extrapolating this result to general membrane fusion confirms that the energy required for pore formation is much larger than the energy required for hemifusion, and may suggest that cooperative protein interactions could assemble after hemifusion in order to advance the evolution of the stalk toward pore formation efficiently[76].

\section{EXPERIMENTAL TECHNIQUES THAT REVEAL DYNAMICS OF MEMBRANE FUSION}

The importance of X-ray crystallography to our understanding of membrane fusion cannot be overstated. Landmark structures of HA, E1, gp41, and gp120 in a variety of pre- and postactivated states have not only given direction to the field of membrane fusion, but were also critical milestones in the field of structural biology[15,18,25,49,50,51,107,108,109]. Electron cryomicroscopy and X-ray crystallography have provided insights into the overall virus particle composition[20,45,104,108,110]. Both techniques can achieve near Á resolution, but provide only static images[111]. Even with images such as the pre- and postfusion configuration of HA, the actual motions and refolding of the protein during the membrane fusion process are unknown. Dynamic measurements of membrane fusion are required to complete our understanding of membrane fusion.

Conductivity measurements have been used to observe dynamic formation of the fusion pore in lipid bilayers and biochemical studies have provided information about the kinetics of the actions of the fusion proteins. Incorporation of fluorescent labels into the virus particles has allowed the most detailed studies of the time course of membrane fusion. For these measurements, fluorescent lipid-like markers are added to the lipid bilayer of viruses, cells, and liposomes, or aqueous fluorescent labels are added to the interior of the compartments. Often, these fluorescent labels are added at high enough concentrations to selfquench, so that on fusion, they mix into the target compartment and dilute, relaxing the quenching and increasing the fluorescence[83,90]. Variations of this assay use resonant energy transfer between two distinct fluorophores to report concentration[112]. Bulk fusion studies using this method have helped determine the lipid composition, $\mathrm{pH}$ conditions, and temperature dependencies of virus-membrane binding and fusion[22,29,33,54,83,90,113,114,115]. 
Greater details of the kinetics of membrane fusion intermediates can be gleaned by using a microscope capable of imaging the fluorescence of individual dye-labeled virus particles. For example, the single-particle approach has directly revealed the times between binding and fusion (when no hemifusion intermediate is detectable), between binding and hemifusion, and between hemifusion and full fusion[23,27,28,58,94]. A recent single-particle fluorescence study of individual influenza particles fusing under acidic conditions with lipid bilayers has discovered the existence of about three intermediate steps between low-pH activation and the quasistable hemifusion stalk state for particles bound to membranes at neutral $\mathrm{pH}$ through receptor interactions[27]. One further single kinetic step was required to proceed from hemifusion to opening of the fusion pore. A different study that examined single influenza virus particles exposed to low $\mathrm{pH}$ before encountering the lipid bilayer found a single step process to hemifusion[58]. Comparing experimental protocols of this sort may allow distinct intermediates in the fusion process to be teased apart. The success of these examples suggests that the single-particle approach holds great promise for future studies of membrane fusion.

The single-particle fluorescent microscopy imaging techniques can be adapted to a number of different configurations. By using streptavidin-coated surfaces, individual biotinylated vesicles can be immobilized on surfaces for imaging[116,117]. The presence of the surface may affect the free energy of the system[118], but the ability to make extended observations of a single virus-liposome complex provides an approach that can overcome the limitations of bulk fusion assays due to the stochastic nature of each fusion event and the difficulty in synchronizing fusion of large ensembles of particles. Liposome targets also allow the role of membrane curvature to be tested in fusion experiments. With all fluorescent labeling experiments, careful consideration of the potential artifacts due to the presence of the label or products of photobleaching the dye labels is important[115]. Interferometric optical detection appears to be a promising technique that is photostable, allows for long time measurements and fast tracking, and leaves the biological system unperturbed. Presently, this technique is difficult to apply within an intact cell[119].

The single-particle fluorescence tracking approach has been used to observe individual virus particles interacting with living cells (for reviews, see [5,120,121,122,123]). Protein dye labels, membrane dye labels, and green fluorescent protein (GFP) have been used to track viruses as they enter the cell and after entry into the cell as they moved towards the nucleus[124,125].

For enveloped viruses, labeling the viral membrane with self-quenched concentrations of fluorescent dye has allowed membrane fusion with cellular membranes to be detected during single-particle tracking experiments[126,127,128,129]. For some viruses, the moment of membrane fusion has been correlated with a sequence of well-defined active transport steps following endocytosis that move the virus to specific locations in the cell[126,129,130]. Double labeling of viruses with pH-sensitive dyes demonstrated that endosomal acidification precedes fusion[129,131]. In influenza, single-particle tracking revealed that fusion occurs during late endosomal acidification near the perinuclear region of the cell typically about $8 \mathrm{~min}$ following the initial binding of the virus to the cell[129]. Single-particle tracking techniques have been used to show that for HIV-1, aqueous contents never transfer before the spread of lipid dye. The time between lipid dye spread and aqueous content transfer is stochastic, sometimes occurring several minutes after the membrane label has disappeared, and is dependent on the target cell type[128]. Recent single-particle tracking of HIV in live cells has concluded that content release only follows lipid mixing when viral particles are endocytosed[43]. This paradigm shifting result demonstrates that measuring biophysical behaviors of viruses in the context of their interactions with living cells can be essential in order to understand their full physiological implications.

\section{MOLECULAR DYNAMICS (MD) SIMULATIONS}

With the current limitations on gathering dynamic experimental data at the nanometer scale with time resolutions under a microsecond, efforts in theoretical and computational modeling have been used to address the dynamics of membrane fusion. These theoretical/computational efforts are challenged by the 
complexity of this phenomenon, which includes protein folding, lipid rearrangement, dependence on the aqueous environments, and possible cooperativity between proteins.

Historically, phenomenological modeling of membranes as elastic materials were the dominant theoretical efforts to model membrane fusion and revealed the general aspects of the hemifusion stalkdiaphragm model[8,9,62]. More recently, MD simulations are addressing the dynamic transitions during membrane fusion. Simulations examining the lipid membrane show the formation of stalks between the diamond cubic phase (QII) to an inverted hexagonal phase (HII)[132]. In these simulations, transmembrane connections precede stalk formation. Forces that tend to minimize the interface curvature affect the transitions between the states. Voids that arise when three monolayers merge can have large free-energy penalties, but these simulations suggest that the lipids tails are flexible enough to fill the bilayer where the monolayers connect[132]. Another MD simulation examined rearrangements when lipids are randomly removed from one monolayer. When more than 12 lipids are removed, the lipids in the intact monolayer will stretch to cover the exposed chains, suggesting a mechanism to generate bending forces in the bilayers by manipulating local lipid density[133].

A course-grain MD simulation of two vesicles fusing due to cross-linker tethering has shown membrane fusion between a pair of 14-nm-diameter vesicles on the hundred-microsecond time scale. The cross-linker is analogous to the prefusion states of HIV gp41, influenza HA, or trans-SNARE complexes. The simulation showed fusion proceeding via a stalk-like intermediate state. About $20 \%$ of vesicles rapidly fuse from the stalk state. The remaining vesicles remained in a long-lived hemifusion intermediate that slowly converted to the fused state. The hemifused intermediate state had a decay half-life of 6.3 $\mu$ sec. In addition to being able to measure $t_{1 / 2}$, the free energy of the stalk-like state $(\Delta \mathrm{G} \mathrm{of}-3.3 \mathrm{kcal} / \mathrm{mol})$ and fused state $(\Delta \mathrm{G}$ of $-6.0 \mathrm{kcal} / \mathrm{mol})$ were determined. However, a determination of the energy of fusion pore expansion did not result from this simulation[134].

Simulations of atomic force microscopy measurements of the cowpea chlorotic mottle virus (CCMV) capsid provided a test bed for modeling forces in the capsid shell lattice that can couple the response of the large structure to local conformational changes[135]. Although the capsid is not involved in membrane fusion for most viruses, similar experiments and analysis of whole alpha- and flavivirus particles might advance our understanding of the large-scale lattice rearrangements of the network of fusion proteins that are present in these highly symmetric particles.

\section{ANTIVIRALS}

Knowledge of the fundamental biophysical properties of viruses can guide research into development of antiviral treatments. For example, understanding of the functional role of the ion channel M2 and the enzyme neuraminase from influenza have allowed us to learn the mode of action of current anti-influenza drugs[136]. Membrane fusion is a basic function important to many viruses that can also be targeted for drug development. Recently, tert-butyl hydroquinone (TBHQ), a known inhibitor of membrane fusion, has been proposed to treat influenza infection. When TBHQ binds in a hydrophobic pocket formed at an interface between HA monomers, it stabilizes the neutral $\mathrm{pH}$ structure of HA, inhibiting the conformational rearrangements required for membrane fusion[109]. Similarly, antibodies that do not prevent cell binding can inactivate influenza by preventing conformational changes in HA that are necessary for membrane fusion[137].

Many of the current antiviral drugs for HIV target reverse transcriptase and HIV Gag protease. Viruses quickly become resistant to these drugs, so an inhibitor that will block the binding between CD4 and HIV's gp120 has been sought. Enfuvirtide (T20) is an FDA-approved antifusion drug that is suggested to interfere with gp41, but viral mutations in the binding site of this drug can lead to decreased efficacy[138,139,140]. C34 is a synthetic peptide that also inhibits fusion between HIV and the target cell by binding to the intermediate conformation of gp41, preventing formation of the six-helix bundle structure necessary for fusion[39,141,142]. Additional experimental HIV fusion inhibitors include, but are not limited to, T-2635, T-651, and bifunctional fusion inhibitors (BFFI)[143], which are generated by 
attaching fusion inhibitors to a CCR5 or CD4 antibody[144]. Complementary approaches focus on blocking the second binding step of gp120 to the cell's coreceptor CCR5 or CXCR4. Naturally occurring anti-CCR5 antibodies have been found that protect against and help control the HIV infection. Already the antiviral PRO-140 has been clinically proven to inhibit binding between CCR5 and gp120. Due to the multistep procedure HIV uses for cell entry, it has been proposed that a CCR5 antibody covalently linked to a fusion peptide inhibitor like enfuvirtide may prevent HIV entry into the cell at multiple steps[143].

The antigenic nature of viruses, variety of viral binding sites, and high virus mutation rates make it difficult for most drugs to remain effective against viruses over time. However, many enveloped viruses employ similar entry mechanisms that require fusion between the viral envelope and cell/endosomal membrane. If a therapeutic strategy is effective against a key biophysical property of membrane fusion, then perhaps drugs targeting this mechanism will remain more effective over time. The commonality of membrane fusion mechanisms among enveloped viruses may allow for similar therapeutic strategies to be employed against many enveloped viruses[141].

\section{CONCLUDING REMARKS AND FUTURE DIRECTIONS}

The study of viral membrane fusion has provided insight into a fundamental process that occurs widely in eukaryotic cell biology. The functional commonality among class I, II, and III viral fusion proteins is surprising considering the diversity of structures and the varied fusion triggers. The current model of viral membrane fusion proposes that a cellular trigger initiates a conformational change in the viral fusion proteins, which exposes a hydrophobic viral fusion peptide. This peptide extends outwards towards and inserts into an apposing cell membrane. The fusion protein then folds back into a hairpin to bring the two apposed membranes together. The subsequent fusion of these membranes is dependent on the lipid composition of the membranes as well as possible additional protein conformational changes and cooperativity among several fusion proteins. The exact mechanisms that lead to lipid mixing are not known, but the precise sequence of the fusion peptide along with the transmembrane domain of the viral fusion protein is indispensable. It is believed that an intermediate hemifusion stalk is formed that then expands into a diaphragm membrane structure. Finally, a fusion pore forms within the diaphragm. The created fusion pore may be stable or may flicker repeatedly before expanding into an opening large enough to allow the genetic material of the virus to enter the cell. The exact nature of these intermediate structures is unknown. Future studies are needed to determine how viral fusion proteins and membrane lipids interact to generate a membrane instability that is large enough to produce membrane fusion.

\section{ACKNOWLEDGMENTS}

The research of KW is supported in part by a CASI award from the Burroughs Wellcome Fund. We thank John Sakon for critically reading the manuscript.

\section{REFERENCES}

1. Brunger, A.T. (2005) Structure and function of SNARE and SNARE-interacting proteins. Q. Rev. Biophys. 38, 1-47.

2. Chen, E.H. and Olson, E.N. (2005) Unveiling the mechanisms of cell-cell fusion. Science 308, 369-373.

3. Chan, D.C. (2006) Mitochondrial fusion and fission in mammals. Annu. Rev. Cell Dev. Biol. 22, 79-99.

4. Primakoff, P. and Myles, D.G. (2007) Cell-cell membrane fusion during mammalian fertilization. FEBS Lett. 581, 2174-2180.

5. Damm, E.M. and Pelkmans, L. (2006) Systems biology of virus entry in mammalian cells. Cell. Microbiol. 8, 12191227.

6. Sollner, T.H. (2004) Intracellular and viral membrane fusion: a uniting mechanism. Curr. Opin. Cell Biol. 16, 429435.

7. Harrison, S.C. (2008) Viral membrane fusion. Nat. Struct. Mol. Biol. 15, 690-698. 
8. Basanez, G. (2002) Membrane fusion: the process and its energy suppliers. Cell. Mol. Life Sci. 59, $1478-1490$.

9. Chernomordik, L.V. and Kozlov, M.M. (2005) Membrane hemifusion: crossing a chasm in two leaps. Cell 123, 375382.

10. Porcar, L., Hamilton, W.A., Butler, P.D., and Warr, G.G. (2004) Topological relaxation of a shear-induced lamellar phase to sponge equilibrium and the energetics of membrane fusion. Phys. Rev. Lett. 93, 198301.

11. Chernomordik, L.V. and Kozlov, M.M. (2008) Mechanics of membrane fusion. Nat. Struct. Mol. Biol. 15, 675-683.

12. Martens, S. and McMahon, H.T. (2008) Mechanisms of membrane fusion: disparate players and common principles. Nat. Rev. Mol. Cell Biol. 9, 543-556.

13. White, J.M., Delos, S.E., Brecher, M., and Schornberg, K. (2008) Structures and mechanisms of viral membrane fusion proteins: multiple variations on a common theme. Crit. Rev. Biochem. Mol. Biol. 43, 189-219.

14. Skehel, J.J. and Wiley, D.C. (2000) Receptor binding and membrane fusion in virus entry: the influenza hemagglutinin. Annu. Rev. Biochem. 69, 531-569.

15. Freed, E.O., Myers, D.J., and Risser, R. (1990) Characterization of the fusion domain of the human immunodeficiency virus type 1 envelope glycoprotein gp41. Proc. Natl. Acad. Sci. U. S. A. 87, 4650-4654.

16. Yang, Z.N., Mueser, T.C., Kaufman, J., Stahl, S.J., Wingfield, P.T., and Hyde, C.C. (1999) The crystal structure of the SIV gp41 ectodomain at 1.47 A resolution. J. Struct. Biol. 126, 131-144.

17. Center, R.J., Kobe, B., Wilson, K.A., Teh, T., Howlett, G.J., Kemp, B.E., and Poumbourios, P. (1998) Crystallization of a trimeric human $\mathrm{T}$ cell leukemia virus type $1 \mathrm{gp} 21$ ectodomain fragment as a chimera with maltose-binding protein. Protein Sci. 7, 1612-1619.

18. Weissenhorn, W., Carfi, A., Lee, K.H., Skehel, J.J., and Wiley, D.C. (1998) Crystal structure of the Ebola virus membrane fusion subunit, GP2, from the envelope glycoprotein ectodomain. Mol. Cell 2, 605-616.

19. Kashiwada, A., Matsuda, K., Mizuno, T., and Tanaka, T. (2008) Construction of a pH-responsive artificial membrane fusion system by using designed coiled-coil polypeptides. Chemistry 14, 7343-7350.

20. Harris, A., Cardone, G., Winkler, D.C., Heymann, J.B., Brecher, M., White, J.M., and Steven, A.C. (2006) Influenza virus pleiomorphy characterized by cryoelectron tomography. Proc. Natl. Acad. Sci. U. S. A. 103, 19123-19127.

21. Stegmann, T., Nir, S., and Wilschut, J. (1989) Membrane-fusion activity of influenza-virus. Effects of gangliosides and negatively charged phospholipids in target liposomes. Biochemistry 28, 1698-1704.

22. Tsao, Y.S. and Huang, L. (1985) Sendai virus induced leakage of liposomes containing gangliosides. Biochemistry 24, 1092-1098.

23. Hinterdorfer, P., Baber, G., and Tamm, L.K. (1994) Reconstitution of membrane fusion sites. A total internal reflection fluorescence microscopy study of influenza hemagglutinin-mediated membrane fusion. J. Biol. Chem. 269, 20360-20368.

24. Matlin, K.S., Reggio, H., Helenius, A., and Simons, K. (1981) Infectious entry pathway of influenza virus in a canine kidney cell line. J. Cell Biol. 91, 601-613.

25. Bullough, P.A., Hughson, F.M., Skehel, J.J., and Wiley, D.C. (1994) Structure of influenza haemagglutinin at the pH of membrane fusion. Nature 371, 37-43.

26. Kielian, M. and Rey, F.A. (2006) Virus membrane-fusion proteins: more than one way to make a hairpin. Nat. Rev. Microbiol. 4, 67-76.

27. Floyd, D.L., Ragains, J.R., Skehel, J.J., Harrison, S.C., and van Oijen, A.M. (2008) Single-particle kinetics of influenza virus membrane fusion. Proc. Natl. Acad. Sci. U. S. A. 105, 15382-15387.

28. Blumenthal, R., Sarkar, D.P., Durell, S., Howard, D.E., and Morris, S.J. (1996) Dilation of the influenza hemagglutinin fusion pore revealed by the kinetics of individual cell-cell fusion events. J. Cell Biol. 135, 63-71.

29. Gunther-Ausborn, S., Schoen, P., Bartoldus, I., Wilschut, J., and Stegmann, T. (2000) Role of hemagglutinin surface density in the initial stages of influenza virus fusion: lack of evidence for cooperativity. J. Virol. 74, 2714-2720.

30. Earp, L.J., Hernandez, L.D., Delos, S.E., and White, J.M. (2003) Receptor-activated binding of viral fusion proteins to target membranes. Methods Enzymol. 372, 428-440.

31. Rawat, S.S., Viard, M., Gallo, S.A., Rein, A., Blumenthal, R., and Puri, A. (2003) Modulation of entry of enveloped viruses by cholesterol and sphingolipids (Review). Mol. Membr. Biol. 20, 243-254.

32. Reeves, J.D., Gallo, S.A., Ahmad, N., Miamidian, J.L., Harvey, P.E., Sharron, M., Pohlmann, S., Sfakianos, J.N., Derdeyn, C.A., Blumenthal, R., Hunter, E., and Doms, R.W. (2002) Sensitivity of HIV-1 to entry inhibitors correlates with envelope/coreceptor affinity, receptor density, and fusion kinetics. Proc. Natl. Acad. Sci. U. S. A. 99, 1624916254.

33. Haque, M.E., Koppaka, V., Axelsen, P.H., and Lentz, B.R. (2005) Properties and structures of the influenza and HIV fusion peptides on lipid membranes: implications for a role in fusion. Biophys. J. 89, 3183-3194.

34. Doms, R.W. and Trono, D. (2000) The plasma membrane as a combat zone in the HIV battlefield. Genes Dev. 14, 2677-2688.

35. Suzuki, T. and Suzuki, Y. (2006) Virus infection and lipid rafts. Biol. Pharm. Bull. 29, 1538-1541.

36. Kwong, P.D., Wyatt, R., Robinson, J., Sweet, R.W., Sodroski, J., and Hendrickson, W.A. (1998) Structure of an HIV gp120 envelope glycoprotein in complex with the CD4 receptor and a neutralizing human antibody. Nature 393, 648659. 
37. Reeves, J.D., Lee, F.H., Miamidian, J.L., Jabara, C.B., Juntilla, M.M., and Doms, R.W. (2005) Enfuvirtide resistance mutations: impact on human immunodeficiency virus envelope function, entry inhibitor sensitivity, and virus neutralization. J. Virol. 79, 4991-4999.

38. Rimsky, L.T., Shugars, D.C., and Matthews, T.J. (1998) Determinants of human immunodeficiency virus type 1 resistance to gp41-derived inhibitory peptides. J. Virol. 72, 986-993.

39. Wild, C.T., Shugars, D.C., Greenwell, T.K., McDanal, C.B., and Matthews, T.J. (1994) Peptides corresponding to a predictive alpha-helical domain of human immunodeficiency virus type 1 gp41 are potent inhibitors of virus infection. Proc. Natl. Acad. Sci. U. S. A. 91, 9770-9774.

40. Furuta, R.A., Wild, C.T., Weng, Y., and Weiss, C.D. (1998) Capture of an early fusion-active conformation of HIV-1 gp41. Nat. Struct. Biol. 5, 276-279.

41. Frey, G., Peng, H., Rits-Volloch, S., Morelli, M., Cheng, Y., and Chen, B. (2008) A fusion-intermediate state of HIV1 gp41 targeted by broadly neutralizing antibodies. Proc. Natl. Acad. Sci. U. S. A. 105, 3739-3744.

42. Munoz-Barroso, I., Durell, S., Sakaguchi, K., Appella, E., and Blumenthal, R. (1998) Dilation of the human immunodeficiency virus-1 envelope glycoprotein fusion pore revealed by the inhibitory action of a synthetic peptide from gp41. J. Cell Biol. 140, 315-323.

43. Miyauchi, K., Kim, Y., Latinovic, O., Morozov, V., and Melikyan, G.B. (2009) HIV enters cells via endocytosis and dynamin-dependent fusion with endosomes. Cell 137, 433-444.

44. Lescar, J., Roussel, A., Wien, M.W., Navaza, J., Fuller, S.D., Wengler, G., and Rey, F.A. (2001) The fusion glycoprotein shell of Semliki Forest virus: an icosahedral assembly primed for fusogenic activation at endosomal $\mathrm{pH}$. Cell 105, 137-148.

45. Zhang, W., Mukhopadhyay, S., Pletnev, S.V., Baker, T.S., Kuhn, R.J., and Rossmann, M.G. (2002) Placement of the structural proteins in Sindbis virus. J. Virol. 76, 11645-11658.

46. Voisset, C. and Dubuisson, J. (2004) Functional hepatitis C virus envelope glycoproteins. Biol. Cell 96, $413-420$.

47. Penin, F., Dubuisson, J., Rey, F.A., Moradpour, D., and Pawlotsky, J.M. (2004) Structural biology of hepatitis C virus. Hepatology 39, 5-19.

48. Op De Beeck, A. and Dubuisson, J. (2003) Topology of hepatitis C virus envelope glycoproteins. Rev. Med. Virol. 13, 233-241.

49. Rey, F.A., Heinz, F.X., Mandl, C., Kunz, C., and Harrison, S.C. (1995) The envelope glycoprotein from tick-borne encephalitis virus at 2 A resolution. Nature 375, 291-298.

50. Modis, Y., Ogata, S., Clements, D., and Harrison, S.C. (2004) Structure of the dengue virus envelope protein after membrane fusion. Nature 427, 313-319.

51. Nybakken, G.E., Nelson, C.A., Chen, B.R., Diamond, M.S., and Fremont, D.H. (2006) Crystal structure of the West Nile virus envelope glycoprotein. J. Virol. 80, 11467-11474.

52. Schibli, D.J. and Weissenhorn, W. (2004) Class I and class II viral fusion protein structures reveal similar principles in membrane fusion (Review). Mol. Membr. Biol. 21, 361-371.

53. Helenius, A., Kartenbeck, J., Simons, K., and Fries, E. (1980) On the entry of Semliki forest virus into BHK-21 cells. J. Cell Biol. 84, 404-420.

54. Smit, J.M., Li, G., Schoen, P., Corver, J., Bittman, R., Lin, K.C., and Wilschut, J. (2002) Fusion of alphaviruses with liposomes is a non-leaky process. FEBS Lett. 521, 62-66.

55. Paredes, A.M., Ferreira, D., Horton, M., Saad, A., Tsuruta, H., Johnston, R., Klimstra, W., Ryman, K., Hernandez, R., Chiu, W., and Brown, D.T. (2004) Conformational changes in Sindbis virions resulting from exposure to low $\mathrm{pH}$ and interactions with cells suggest that cell penetration may occur at the cell surface in the absence of membrane fusion. Virology 324, 373-386.

56. Wang, G., Hernandez, R., Weninger, K., and Brown, D.T. (2007) Infection of cells by Sindbis virus at low temperature. Virology 362, 461-467.

57. Mukhopadhyay, S., Zhang, W., Gabler, S., Chipman, P.R., Strauss, E.G., Strauss, J.H., Baker, T.S., Kuhn, R.J., and Rossmann, M.G. (2006) Mapping the structure and function of the E1 and E2 glycoproteins in alphaviruses. Structure 14, 63-73.

58. Wessels, L., Elting, M.W., Scimeca, D., and Weninger, K. (2007) Rapid membrane fusion of individual virus particles with supported lipid bilayers. Biophys. J. 93, 526-538.

59. Zaitseva, E., Mittal, A., Griffin, D.E., and Chernomordik, L.V. (2005) Class II fusion protein of alphaviruses drives membrane fusion through the same pathway as class I proteins. J. Cell Biol. 169, 167-177.

60. Gibbons, D.L., Vaney, M.C., Roussel, A., Vigouroux, A., Reilly, B., Lepault, J., Kielian, M., and Rey, F.A. (2004) Conformational change and protein-protein interactions of the fusion protein of Semliki Forest virus. Nature 427, 320-325.

61. Jardetzky, T.S. and Lamb, R.A. (2004) Virology: a class act. Nature 427, 307-308.

62. Cohen, F.S. and Melikyan, G.B. (2004) The energetics of membrane fusion from binding, through hemifusion, pore formation, and pore enlargement. J. Membr. Biol. 199, 1-14.

63. Weissenhorn, W., Hinz, A., and Gaudin, Y. (2007) Virus membrane fusion. FEBS Lett. 581, 2150-2155.

64. Kadlec, J., Loureiro, S., Abrescia, N.G., Stuart, D.I., and Jones, I.M. (2008) The postfusion structure of baculovirus gp64 supports a unified view of viral fusion machines. Nat. Struct. Mol. Biol. 15, 1024-1030. 
65. Roche, S., Bressanelli, S., Rey, F.A., and Gaudin, Y. (2006) Crystal structure of the low-pH form of the vesicular stomatitis virus glycoprotein G. Science 313, 187-191.

66. Heldwein, E.E., Lou, H., Bender, F.C., Cohen, G.H., Eisenberg, R.J., and Harrison, S.C. (2006) Crystal structure of glycoprotein B from herpes simplex virus 1. Science 313, 217-220.

67. Gaudin, Y. (2000) Rabies virus-induced membrane fusion pathway. J. Cell Biol. 150, 601-612.

68. Markovic, I., Pulyaeva, H., Sokoloff, A., and Chernomordik, L.V. (1998) Membrane fusion mediated by baculovirus gp64 involves assembly of stable gp64 trimers into multiprotein aggregates. J. Cell Biol. 143, 1155-1166.

69. Wickner, W. and Schekman, R. (2008) Membrane fusion. Nat. Struct. Mol. Biol. 15, 658-664.

70. Liu, T., Wang, T., Chapman, E.R., and Weisshaar, J.C. (2008) Productive hemifusion intermediates in fast vesicle fusion driven by neuronal SNAREs. Biophys. J. 94, 1303-1314.

71. Bowen, M.E., Weninger, K., Brunger, A.T., and Chu, S. (2004) Single molecule observation of liposome-bilayer fusion thermally induced by soluble N-ethyl maleimide sensitive-factor attachment protein receptors (SNAREs). Biophys. J. 87, 3569-3584. Parpura, V. and Mohideen, U. (2008) Molecular form follows function: (un)snaring the SNAREs. Trends Neurosci. 31, 435-443.

73. Rizo, J. and Rosenmund, C. (2008) Synaptic vesicle fusion. Nat. Struct. Mol. Biol. 15, 665-674.

74. Sutton, R.B., Fasshauer, D., Jahn, R., and Brunger, A.T. (1998) Crystal structure of a SNARE complex involved in synaptic exocytosis at 2.4 A resolution. Nature 395, 347-353.

75. Antonin, W., Fasshauer, D., Becker, S., Jahn, R., and Schneider, T.R. (2002) Crystal structure of the endosomal SNARE complex reveals common structural principles of all SNAREs. Nat. Struct. Biol. 9, 107-111.

76. Malinin, V.S. and Lentz, B.R. (2004) Energetics of vesicle fusion intermediates: comparison of calculations with observed effects of osmotic and curvature stresses. Biophys. J. 86, 2951-2964. Farsad, K. and De Camilli, P. (2003) Mechanisms of membrane deformation. Curr. Opin. Cell Biol. 15, 372-381.

Lang, T., Halemani, N.D., and Rammner, B. (2008) Interplay between lipids and the proteinaceous membrane fusion machinery. Prog. Lipid Res. 47, 461-469.

Waarts, B.L., Bittman, R., and Wilschut, J. (2002) Sphingolipid and cholesterol dependence of alphavirus membrane fusion. Lack of correlation with lipid raft formation in target liposomes. J. Biol. Chem. 277, 38141-38147.

80. Rawicz, W., Smith, B.A., McIntosh, T.J., Simon, S.A., and Evans, E. (2008) Elasticity, strength, and water permeability of bilayers that contain raft microdomain-forming lipids. Biophys. J. 94, 4725-4736.

81. Hung, W.C., Lee, M.T., Chen, F.Y., and Huang, H.W. (2007) The condensing effect of cholesterol in lipid bilayers. Biophys. J. 92, 3960-3967.

82. Vashishtha, M., Phalen, T., Marquardt, M.T., Ryu, J.S., Ng, A.C., and Kielian, M. (1998) A single point mutation controls the cholesterol dependence of Semliki Forest virus entry and exit. J. Cell Biol. 140, 91-99.

83. Smit, J.M., Waarts, B.L., Bittman, R., and Wilschut, J. (2003) Liposomes as target membranes in the study of virus receptor interaction and membrane fusion. Methods Enzymol. 372, 374-392.

84. Chernomordik, L.V., Frolov, V.A., Leikina, E., Bronk, P., and Zimmerberg, J. (1998) The pathway of membrane fusion catalyzed by influenza hemagglutinin: Restriction of lipids, hemifusion, and lipidic fusion pore formation. $J$. Cell Biol. 140, 1369-1382.

85. Chernomordik, L.V., Vogel, S.S., Sokoloff, A., Onaran, H.O., Leikina, E.A., and Zimmerberg, J. (1993) Lysolipids reversibly inhibit $\mathrm{Ca}(2+)-$, GTP- and $\mathrm{pH}$-dependent fusion of biological membranes. FEBS Lett. 318, 71-76.

86. Agrawal, P., Kiihne, S., Hollander, J., Hulsbergen, F., Hofmann, M., Langosch, D., and de Groot, H. (2007) Solid state NMR investigation of the interaction between biomimetic lipid bilayers and de novo designed fusogenic peptides. Chembiochem 8, 493-496.

87. Chernomordik, L., Chanturiya, A., Green, J., and Zimmerberg, J. (1995) The hemifusion intermediate and its conversion to complete fusion: regulation by membrane composition. Biophys. J. 69, 922-929.

88. Yang, L. and Huang, H.W. (2002) Observation of a membrane fusion intermediate structure. Science 297, 18771879.

89. Gruner, S.M. (2002) Caught in the act. Science 297, 1817-1818.

90. Nunes-Correia, I., Eulalio, A., Nir, S., Duzgunes, N., Ramalho-Santos, J., and Pedroso de Lima, M.C. (2002) Fluorescent probes for monitoring virus fusion kinetics: comparative evaluation of reliability. Biochim. Biophys. Acta 1561, 65-75.

91. Razinkov, V.I., HernandezJimenez, E.I., Mikhalyov, I.I., Cohen, F.S., and Molotkovsky, J.G. (1997) New fluorescent lysolipids: preparation and selective labeling of inner liposome leaflet. Biochim. Biophys. Acta 1329, 149-158.

92. Bonnafous, P. and Stegmann, T. (2003) Pore formation in target liposomes by viral fusion proteins. Methods Enzymol. 372, 408-418.

93. Chizmadzhev, Y.A. (2004) The mechanisms of lipid-protein rearrangements during viral infection. Bioelectrochemistry 63, 129-136.

94. Yoon, T.Y., Lu, X., Diao, J., Lee, S.M., Ha, T., and Shin, Y.K. (2008) Complexin and Ca2+ stimulate SNAREmediated membrane fusion. Nat. Struct. Mol. Biol. 15, 707-713.

95. Estes, D.J., Lopez, S.R., Fuller, A.O., and Mayer, M. (2006) Triggering and visualizing the aggregation and fusion of lipid membranes in microfluidic chambers. Biophys. J. 91, 233-243. 
96. Melikyan, G.B., White, J.M., and Cohen, F.S. (1995) GPI-anchored influenza hemagglutinin induces hemifusion to both red blood cell and planar bilayer membranes. J. Cell Biol. 131, 679-691.

97. Kemble, G.W., Henis, Y.I., and White, J.M. (1993) GPI- and transmembrane-anchored influenza hemagglutinin differ in structure and receptor binding activity. J. Cell Biol. 122, 1253-1265.

98. Kemble, G.W., Danieli, T., and White, J.M. (1994) Lipid-anchored influenza hemagglutinin promotes hemifusion, not complete fusion. Cell 76, 383-391.

99. Schroth-Diez, B., Ludwig, K., Baljinnyam, B., Kozerski, C., Huang, Q., and Herrmann, A. (2000) The role of the transmembrane and of the intraviral domain of glycoproteins in membrane fusion of enveloped viruses. Biosci. Rep. 20, 571-595.

100. Chatterjee, P.K., Vashishtha, M., and Kielian, M. (2000) Biochemical consequences of a mutation that controls the cholesterol dependence of Semliki Forest virus fusion. J. Virol. 74, 1623-1631.

101. Duffus, W.A., Levy-Mintz, P., Klimjack, M.R., and Kielian, M. (1995) Mutations in the putative fusion peptide of Semliki Forest virus affect spike protein oligomerization and virus assembly. J. Virol. 69, 2471-2479.

102. West, J., Hernandez, R., Ferreira, D., and Brown, D.T. (2006) Mutations in the endodomain of Sindbis virus glycoprotein E2 define sequences critical for virus assembly. J. Virol. 80, 4458-4468.

103. Whitehurst, C.B., Willis, J.H., Sinodis, C.N., Hernandez, R., and Brown, D.T. (2006) Single and multiple deletions in the transmembrane domain of the Sindbis virus E2 glycoprotein identify a region critical for normal virus growth. Virology 347, 199-207.

104. Navaratnarajah, C.K. and Kuhn, R.J. (2007) Functional characterization of the Sindbis virus E2 glycoprotein by transposon linker-insertion mutagenesis. Virology 363, 134-147.

105. Epand, R.M. (2003) Fusion peptides and the mechanism of viral fusion. Biochim. Biophys. Acta 1614, 116-121.

106. Hua, Y. and Scheller, R.H. (2001) Three SNARE complexes cooperate to mediate membrane fusion. Proc. Natl. Acad. Sci. U. S. A. 98, 8065-8070.

107. Wilson, I.A., Skehel, J.J., and Wiley, D.C. (1981) Structure of the haemagglutinin membrane glycoprotein of influenza virus at 3 A resolution. Nature 289, 366-373.

108. Kanaseki, T., Kawasaki, K., Murata, M., Ikeuchi, Y., and Ohnishi, S. (1997) Structural features of membrane fusion between influenza virus and liposome as revealed by quick-freezing electron microscopy. J. Cell Biol. 137, 10411056.

109. Russell, R.J., Kerry, P.S., Stevens, D.J., Steinhauer, D.A., Martin, S.R., Gamblin, S.J., and Skehel, J.J. (2008) Structure of influenza hemagglutinin in complex with an inhibitor of membrane fusion. Proc. Natl. Acad. Sci. U. S. A. 105, 17736-17741.

110. von Bonsdorf, C.H. and Harrison, S.C. (1975) Sindbis virus glycoproteins form a regular icosahedral surface lattice. J. Virol. 16, 141-145.

111. Curtis, H. (1989) Biology. Worth, New York.

112. Yoon, T.Y., Okumus, B., Zhang, F., Shin, Y.K., and Ha, T. (2006) Multiple intermediates in SNARE-induced membrane fusion. Proc. Natl. Acad. Sci. U. S. A. 103, 19731-19736.

113. Peisajovich, S.G. and Shai, Y. (2003) Liposomes in identification and characterization of viral fusogenic peptides. Methods Enzymol. 372, 361-373.

114. Ohki, S., Flanagan, T.D., and Hoekstra, D. (1998) Probe transfer with and without membrane fusion in a fluorescence fusion assay. Biochemistry 37, 7496-7503.

115. Thongthai, W. and Weninger, K. (2008) Photoinactivation of Sindbis virus infectivity without inhibition of membrane fusion. Photochem. Photobiol. 85, 801-806.

116. Yoshina-Ishii, C. and Boxer, S.G. (2003) Arrays of mobile tethered vesicles on supported lipid bilayers. J. Am. Chem. Soc. 125, 3696-3697.

117. Boukobza, E., Sonnenfeld, A., and Haran, G. (2001) Immobilization in surface-tethered lipid vesicles as a new tool for single biomolecule spectroscopy. J. Phys. Chem. B 105, 12165-12170.

118. Manley, S., Horton, M.R., Lecszynski, S., and Gast, A.P. (2008) Sorting of streptavidin protein coats on phaseseparating model membranes. Biophys. J. 95, 2301-2307.

119. Ewers, H., Jacobsen, V., Klotzsch, E., Smith, A.E., Helenius, A., and Sandoghdar, V. (2007) Label-free optical detection and tracking of single virions bound to their receptors in supported membrane bilayers. Nano Lett. 7, 22632266.

120. Greber, U.F. and Way, M. (2006) A superhighway to virus infection. Cell 124, 741-754.

121. Marsh, M. and Helenius, A. (2006) Virus entry: open sesame. Cell 124, 729-740.

122. Pelkmans, L. and Helenius, A. (2003) Insider information: what viruses tell us about endocytosis. Curr. Opin. Cell Biol. 15, 414-422.

123. Brandenburg, B. and Zhuang, X. (2007) Virus trafficking - learning from single-virus tracking. Nat. Rev. Microbiol. 5, 197-208.

124. Seisenberger, G., Ried, M.U., Endress, T., Buning, H., Hallek, M., and Brauchle, C. (2001) Real-time single-molecule imaging of the infection pathway of an adeno-associated virus. Science 294, 1929-1932.

125. Finke, S., Brzozka, K., and Conzelmann, K.K. (2004) Tracking fluorescence-labeled rabies virus: enhanced green fluorescent protein-tagged phosphoprotein $\mathrm{P}$ supports virus gene expression and formation of infectious particles. $J$. Virol. 78, 12333-12343. 
126. van der Schaar, H.M., Rust, M.J., Waarts, B.L., van der Ende-Metselaar, H., Kuhn, R.J., Wilschut, J., Zhuang, X., and Smit, J.M. (2007) Characterization of the early events in dengue virus cell entry by biochemical assays and singlevirus tracking. J. Virol. 81, 12019-12028.

127. Melikyan, G.B., Barnard, R.J., Abrahamyan, L.G., Mothes, W., and Young, J.A. (2005) Imaging individual retroviral fusion events: from hemifusion to pore formation and growth. Proc. Natl. Acad. Sci. U. S. A. 102, 8728-8733.

128. Markosyan, R.M., Cohen, F.S., and Melikyan, G.B. (2005) Time-resolved imaging of HIV-1 Env-mediated lipid and content mixing between a single virion and cell membrane. Mol. Biol. Cell 16, 5502-5513.

129. Lakadamyali, M., Rust, M.J., Babcock, H.P., and Zhuang, X. (2003) Visualizing infection of individual influenza viruses. Proc. Natl. Acad. Sci. U. S. A. 100, 9280-9285.

130. Lakadamyali, M., Rust, M.J., and Zhuang, X. (2004) Endocytosis of influenza viruses. Microbes Infect. 6, 929-936.

131. Jaiswal, J.K. and Simon, S.M. (2007) Imaging single events at the cell membrane. Nat. Chem. Biol. 3, 92-98.

132. Marrink, S.J. and Tieleman, D.P. (2002) Molecular dynamics simulation of spontaneous membrane fusion during a cubic-hexagonal phase transition. Biophys. J. 83, 2386-2392.

133. Tieleman, D.P. and Bentz, J. (2002) Molecular dynamics simulation of the evolution of hydrophobic defects in one monolayer of a phosphatidylcholine bilayer: relevance for membrane fusion mechanisms. Biophys. J. 83, 1501-1510.

134. Kasson, P.M., Kelley, N.W., Singhal, N., Vrljic, M., Brunger, A.T., and Pande, V.S. (2006) Ensemble molecular dynamics yields submillisecond kinetics and intermediates of membrane fusion. Proc. Natl. Acad. Sci. U. S. A. 103, $11916-11921$.

135. Gibbons, M.M. and Klug, W.S. (2008) Influence of nonuniform geometry on nanoindentation of viral capsids. Biophys. J. 95, 3640-3649.

136. Tumpey, T.M., Garcia-Sastre, A., Mikulasova, A., Taubenberger, J.K., Swayne, D.E., Palese, P., and Basler, C.F. (2002) Existing antivirals are effective against influenza viruses with genes from the 1918 pandemic virus. Proc. Natl. Acad. Sci. U. S. A. 99, 13849-13854.

137. Sui, J., Hwang, W.C., Perez, S., Wei, G., Aird, D., Chen, L.M., Santelli, E., Stec, B., Cadwell, G., Ali, M., Wan, H., Murakami, A., Yammanuru, A., Han, T., Cox, N.J., Bankston, L.A., Donis, R.O., Liddington, R.C., and Marasco, W.A. (2009) Structural and functional bases for broad-spectrum neutralization of avian and human influenza A viruses. Nat. Struct. Mol. Biol. 16, 265-273.

138. Kilby, J.M., Hopkins, S., Venetta, T.M., DiMassimo, B., Cloud, G.A., Lee, J.Y., Alldredge, L., Hunter, E., Lambert, D., Bolognesi, D., Matthews, T., Johnson, M.R., Nowak, M.A., Shaw, G.M., and Saag, M.S. (1998) Potent suppression of HIV-1 replication in humans by T-20, a peptide inhibitor of gp41-mediated virus entry. Nat. Med. 4, 1302-1307.

139. Poveda, E., Briz, V., and Soriano, V. (2005) Enfuvirtide, the first fusion inhibitor to treat HIV infection. AIDS Rev. 7, 139-147.

140. Strockbine, B. and Rizzo, R.C. (2007) Binding of antifusion peptides with HIVgp41 from molecular dynamics simulations: quantitative correlation with experiment. Proteins 67, 630-642.

141. Eckert, D.M. and Kim, P.S. (2001) Mechanisms of viral membrane fusion and its inhibition. Annu. Rev. Biochem. 70, 777-810.

142. Markosyan, R.M., Cohen, F.S., and Melikyan, G.B. (2005) Time-resolved imaging of HIV-1 Env-mediated lipid and content mixing between a single virion and cell membrane. Mol. Biol. Cell 16, 5502-5513.

143. Kopetzki, E., Jekle, A., Ji, C., Rao, E., Zhang, J., Fischer, S., Cammack, N., Sankuratri, S., and Heilek, G. (2008) Closing two doors of viral entry: intramolecular combination of a coreceptor- and fusion inhibitor of HIV-1. Virol. J. $5,56$.

144 Ji, C., Kopetzki, E., Jekle, A., Stubenrauch, K.-G., Liu, X., Zhang, J., Rao, E., Schlothauer, T., Fischer, S., Cammack, N., Heilek, G., Ries, S., and Sankuratri, S. (2009) CD4-anchoring HIV-1 fusion inhibitor with enhanced potency and in vivo stability. J. Biol. Chem. 284, 5175-5185.

\section{This article should be cited as follows:}

Wessels, L. and Weninger, K. (2008) Physical aspects of viral membrane fusion. TheScientificWorldJOURNAL 9, 764-780. DOI 10.1100/tsw.2009.76. 

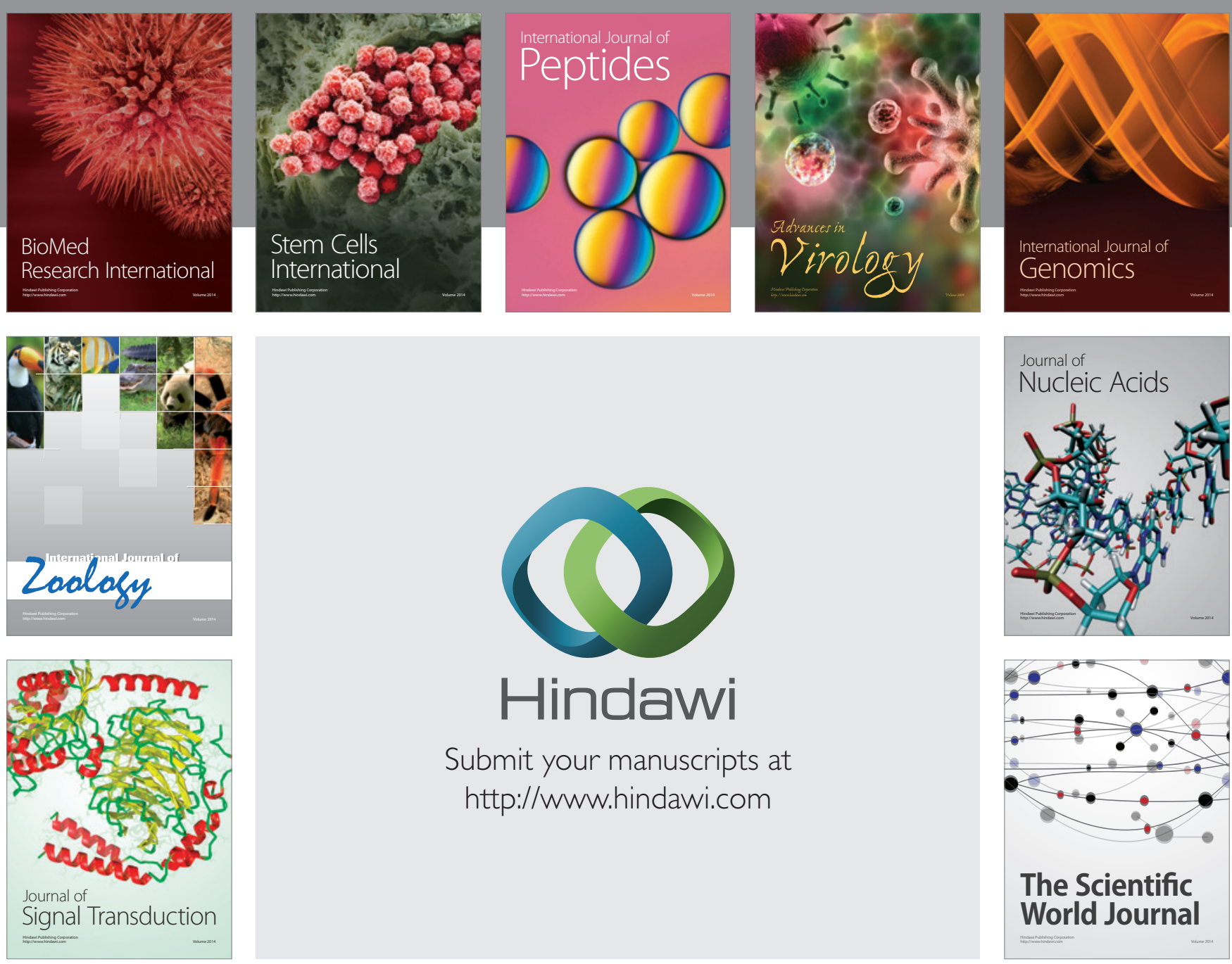

Submit your manuscripts at

http://www.hindawi.com
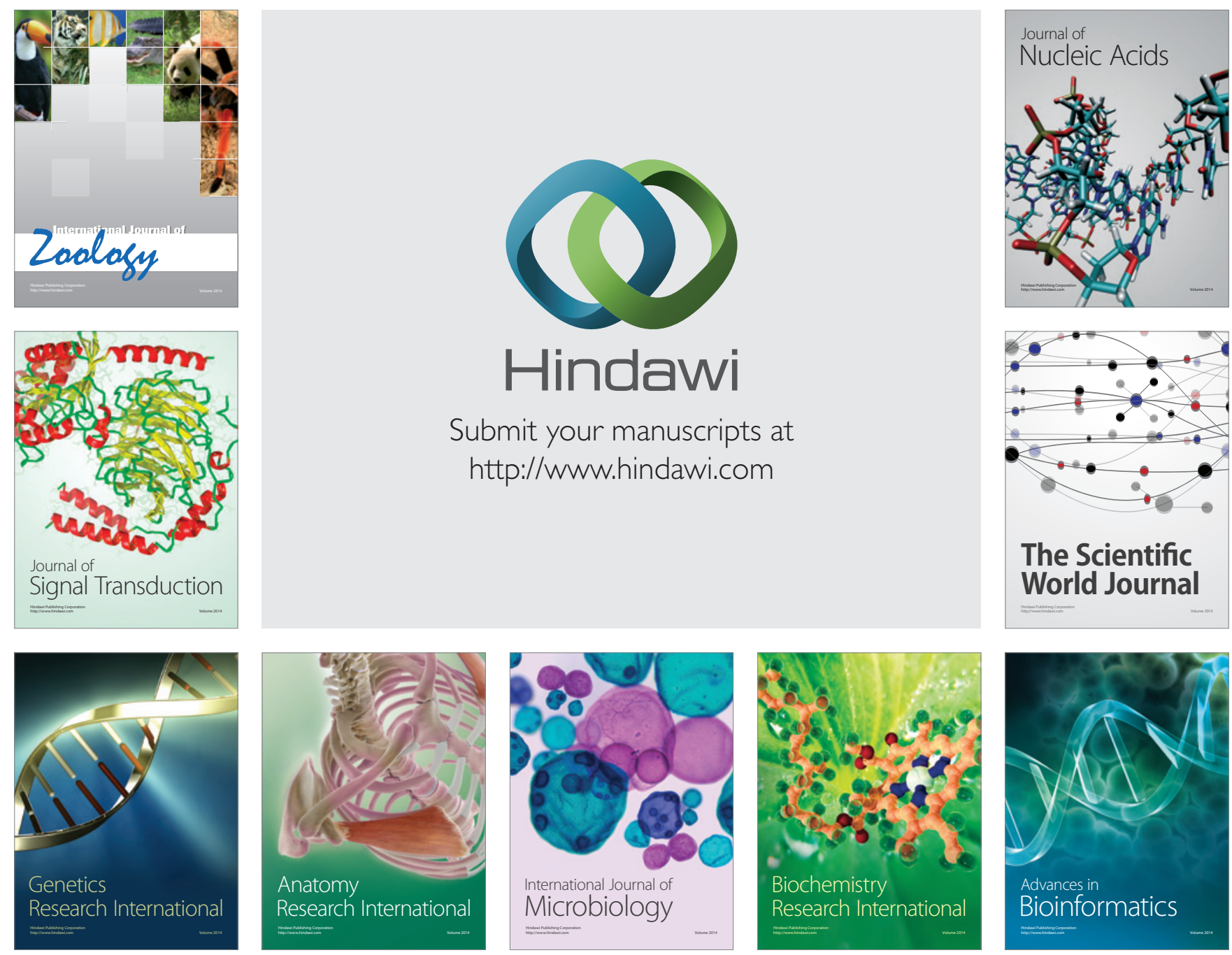

The Scientific World Journal
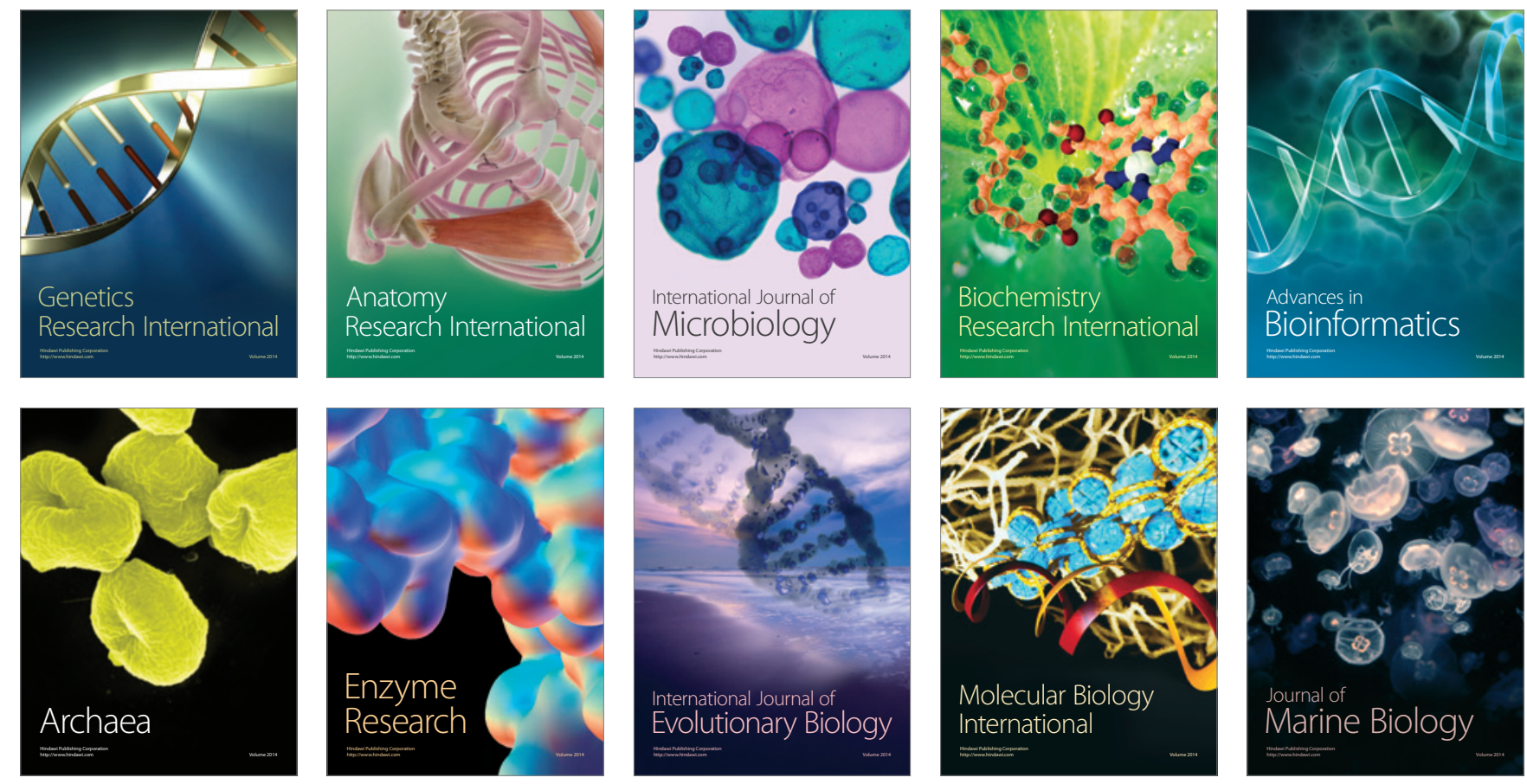